\title{
Entre el elogio banal y el insulto soez: la vulgaridad como amenaza a la colectividad obrera en Mano de obra de Diamela Eltit
} Between Banal Praise and Vile Insults: Vulgarity as a Threat to the Working Community in Diamela Eltit's Mano de obra

\author{
Dianna C. Niebylski \\ University of Illinois at Chicago
}

Partiendo de la premisa que Mano de obra de Diamela Eltit escenifica y hace audible la relación entre economía (neo)liberal y retórica, este ensayo se concentra en la segunda parte de la novela para notar la doble retórica que caracteriza a la voz en primera persona plural a través de "Puro Chile". Por una parte esta voz narrativa reproduce un registro verbal caracterizado por su excesiva -y banal-cordialidad; por otra, la misma voz se trastoca constantemente en insultos agresivos, vulgares y típicamente chilenos. Si bien cada viñeta se inicia con elogios y reconocimientos del aprecio mutuo entre los miembros del grupo, el temor al desempleo, la falta de alimentos, de agua y de luz resultan en la jerga obscena y furiosa en que decae este esfuerzo de solidaridad. Este contraste antagónico refleja la tensión entre lo que Rossana Reguillo ha llamado "la palabra blanca" y el habla de un sector obrero que ya no cree o no puede formar parte de un diálogo colectivo. Junto con una fulminante descomposición física y ambiental, la pérdida de una gramática y una retórica que se preste al diálogo apunta a la poca o nula posibilidad de que los empleados y despedidos puedan mantener intacto la pequeña familia que intentan formar.

Palabras clave: Diamela Eltit, Mano de obra, retórica, economía, mercado, (neo)liberalismo, Andrés Bello, Adam Smith, vulgaridad.

By highlighting the fraught relationship between rhetoric and economics, Eltit's Mano de obra wields and references different rhetorical and aesthetic styles to expose the disintegration of working-class solidarity as the ultimate consequence of the liberal economics that characterized Chile's economy from the second half of the nineteenth century to its present neoliberal manifestation. This essay focuses on the second part of the novel and the antagonism between the two types of rhetoric that characterize the first person plural narrative voice. On the one hand, this communal voice insists time and again on expressing appreciation, respect and mutual affection for any and all members of the group. On the other, this same voice is punctuated by vulgar and aggressive insults as each and every member of the group collapses under the pressure of fear, betrayal and the occasional self- mutilation. This verbal disintegration makes loudly audible the imminent demise of the fragile community on which these workers depended for their survival.

Keywords: Diamela Eltit, Mano de obra, rhetoric, economics, (neo)liberalism, Andrés Bello, Adam Smith, vulgarity. 
"porque si no, concha de tu madre, te echamos cagando de aquí y cambia la cara culiado, cámbiala, ¿me oís? O te vai ahora mismo, salís cagando en este instante porque estos maricones tienen que comprar las papayas ahora mismo ¿entendiste, huevón? y aperra el micrófono, de buenas ganas, sin ponerme esa cara de poto... antes de que los tarros culiados se vayan a la misma chucha".

Mano de obra (158)

"El lenguaje de la miseria está hecho de gruñidos... La pobreza empieza por la precariedad de la sintaxis".

Javier Moreno, $2020^{1}$

La obra de Diamela Eltit busca insistentemente dejar constancia de lo irrepresentable de la pobreza, del hambre $y$, en sus obras más recientes, de la violencia del mercado neoliberal: condiciones, experiencias y sensaciones antitéticas a la pulcritud, la corrección o al control y la "propiedad" en la expresión. El lenguaje forcejado, a veces barroco y con frecuencia distorsionado es ya marca registrada de la obra de esta autora, pero en las novelas escritas a partir del 2000, la narración explota con frecuencia en el insulto a la vez agresivo y vulgar. En sus novelas, el rechazo de la corrección en lo lingüístico y en el comportamiento de sus narradores y personajes es generalmente el efecto de la rabia o de la impotencia de estos. En Mano de obra, ira, humillación, ansiedad y desconfianza son las sensaciones que invaden los cuerpos que van desmejorando, enfermando o descomponiéndose en la novela. Provocadas por el irreparable hundimiento económico y somático que experimentan los personajes, estas sensaciones se concentran en la lengua.

Si la primera parte de la novela ("El Despertar de los trabajadores") verbaliza mayormente la desintegración psíquica y física del empleado, en la segunda parte esta desintegración (ahora claramente múltiple y plural) se intensifica bajo el constante y cada vez más intenso temor al despido y a la vivienda que comparten. El empleado-narrador de la primera parte se lamenta de su lengua hipertrófica, una lengua que, bajo la influencia del pisco, termina puteando a Dios y a sus representantes. Es en la segunda parte de la novela, sin embargo, que esta lengua sucia, hambrienta y temerosa completa el ciclo de degeneración al no poder impedir que casi todo intento de cortesía y reconocimiento dentro de la pequeña familia postiza que protagoniza "Puro Chile". Junto con una acelerada descomposición física y ambiental, entonces, esta segunda parte registra también la pérdida de una modalidad expresiva adecuada al diálogo. De ese modo hace audible la poca o nula posibilidad de que los empleados y despedidos que comparten techo y comida puedan salir del círculo vicioso de hostilidad y animosidad en que han caído. Este ensayo enfoca en la segunda parte de Mano de obra, en

1 Ver entrevista de Hacier Larretxea con el novelista español. 
parte para examinar la doble retórica que rige la voz narrativa, y en parte para notar la relación entre la degradación del habla de los empleados y la desintegración al pequeño colectivo laboral-familiar con el que esperaban resistir la degradación y la exclusión a la que el mercado (el supermercado) los expone. ${ }^{2}$

"Puro Chile", el subtítulo de esta segunda parte, hace alusión al periódico chileno más representativo de las voces obreras y de Unidad Popular durante la presidencia de Salvador Allende. Dicho periódico empezó a circular en 1970 con la elección de Allende, y fue clausurado en 1973, el día después del golpe de Estado ${ }^{3}$. Conocido por su estilo irreverente y frecuentemente ofensivo, el periódico-tabloide hacía uso de expresiones vulgares típicas de la retórica chilena popular con el fin de lograr que su sátira política tuviese un máximo efecto. No hay duda alguna, sin embargo, que detrás del lenguaje desenfadado y obsceno de los titulares y las caricaturas había una voz crítica que acusaba la desigualdad social, la hipocresía y la corrupción, y que incitaba a los seguidores de la Unidad Popular a mantenerse solidarios ante la oposición que quería silenciarlos y destruirlos. En la novela, en cambio, la descomposición y progresiva corrupción de la comunicación necesaria para mantener un mínimo contrato social refleja la inevitable desintegración de la unidad obrera ante un mercado no solo cada vez más global, sino cada vez más anónimo e inhumano ${ }^{4}$.

Cabe notar desde un inicio, sin embargo, que el vulgar insulto no es la única modalidad retórica en la segunda parte de la novela. Aunque hasta ahora casi todo estudio o reseña sobre esta novela no deja de observar el uso de la palabra soez en "Puro Chile", ni reseñadores ni críticos se han detenido a señalar que la voz narrativa en primera persona plural que narra esta segunda parte de la novela se tensa entre dos códigos retóricos: si bien las obscenidades que se van acumulando a través de "Puro Chile" suscitan una impresión y un efecto inmediato y duradero, es importante reconocer que cada fragmento o viñeta comienza con expresiones de aprecio y solidaridad. Es cierto que se trata de una expresión de cordialidad tan banal que resulta fácil considerarla sarcástica (o paródica), pero aun si así fuera la repetición del gesto una y otra vez denota el esfuerzo de los varios miembros del grupo por mantener vivo el instinto solidario o colectivo con que acordaron compartir casa y comida.

\footnotetext{
2 Para una lectura mucho más extensa de la novela, ver mi artículo "Gramáticas capitalistas, retóricas contra-hegemónicas y la prensa obrera chilena", que será publicada aproximadamente al mismo tiempo que esta revista en Pobreza y precariedad en el imaginario Latinoamericano del siglo XXI, coeditado por Stephen Buttes y Dianna Niebylski.

3 El periódico, fundado por el periodista Eugenio Lira Massi y José Gómez López, empezó a circular con las elecciones de Allende en 1970 y fue cerrado el día después del golpe de Estado de 1973. Lira Massi debió exiliarse inmediatamente con la caída de Allende y se mudó a Francia. Muchos creen que su muerte, poco tiempo después, fue un asesinato político. Este periódico se caracterizaba por "virulentas críticas y una retórica ofensiva y a veces obscena" (Ver "La prensa chucheta en Chile" (s.p.).

4 En uno de los primeros artículos sobre la "mala palabra" en esta novela, Jean Franco mantiene que el insulto o la palabra soez es la única señal de que aún queda una cifra de identidad colectiva chilena en la novela. Aunque en un primer momento me resultó convincente esta lectura, he llegado a la conclusión contraria.
} 
Particularmente en los primeros capítulos de esta segunda parte, la explosión de vulgaridades se inserta entre expresiones de reconocimiento de la generosidad, limpieza, seducción, habilidad, o talento de los compañeros que han decidido vivir bajo el mismo techo. Se dice, por ejemplo, que "Isabel era una promotora excelente" (81); Gloria "era honrada y era limpia. Caminaba cuatro cuadras para encontrar las últimas ofertas del día... realizaba verdaderos milagros con la plata" (86); "Enrique era tan generoso con nosotros..." (93); Sonia "no era bonita... Pero poseía otras cualidades" (106); Pedro "era un cazador brillante, un experto en pistas, en rostros, en modales, en gestos, en intenciones, en formas" (137). Todos y cada miembro del grupo reciben su cumplido en algún momento. Junto con estos elogios y señales de reconocimiento, la voz narrativa no deja de repetir que entre ellos hay un afecto mutuo: "Nosotros queríamos a Sonia. La queríamos aunque ella nos había tratado con excesiva frialdad" (105); "Resultaba reconfortante, después de todo, que Enrique nos quisiera tanto" (93); Andrés "[n]os quería tanto. Nos trataba con una consideración extraordinaria" (114); Isabel ... era tan buena que nos quería a todos de la misma manera y con igual intensidad)"(114). La insistencia con que esta voz repite cuánto se quieren y se respetan es señal inconfundible de que detrás de estas afirmaciones se esconde el temor de que ni el respeto ni el aprecio sean sinceros o mutuos.

Como noté anteriormente, la banalidad y la exageración que caracterizan las expresiones de cortesía y afecto pueden fácilmente convencernos de que esta retórica, a diferencia de los insultos, es meramente paródica, irónica o sarcástica. Pero también puede verse como solo un intento fallido de reproducir un registro retórico al que los miembros del grupo están poco acostumbrados. A juzgar por la frecuencia con que varios de los personajes reprueban a otro por su vulgaridad, parecería evidente que algunos de ellos no han desistido de la posibilidad de dominar el habla de una clase media o una clase trabajadora respetable al comienzo de la segunda parte de la novela. Aún si solo logra una imitación poco sincera, el esfuerzo por imitar los buenos modales que el grupo parece asociar con una clase media mínimamente estable y acomodada no debe pasar inadvertido.

A medida que los empleados van perdiendo horas de trabajo, equipos electrónicos, la electricidad y el agua potable, sin embargo, el elogio y las expresiones de afecto se tornan en vituperio más y más rápidamente. De este modo la novela dramatiza lo absurdo y lo vacío de una sintaxis que resulta totalmente inapropiada a la violenta precariedad y al estado de emergencia en que viven estos sujetos. Con más y más frecuencia, los elogios o expresiones valorativas positivas se trastocan en insultos, muchas veces en el mismo párrafo o en la misma oración. Al final del mismo segmento en que admiten que "Enrique era tan generoso" porque les permitía "mirar los programas en su tele", Enrique pide la ayuda del grupo para pagar la cuota de su equipo electrónico para que no se lo quiten por no haber pagado la cuota mensual. Los demás se niegan terminantemente, y lo que hace unas horas era generosidad de parte de Enrique, de repente es "una huevada": "Enrique siempre ha sido bastante huevón con la plata" (96). Después de notar que Isabel "quería y respetaba a Alberto" (88), al enterarse de que dicho Alberto está organizando un sindicato (lo que puede peligrar los puestos de los demás al enterarse los supervisores que comparten casa), Isabel 
exclama: "cómo Alberto podía ser tan mierda, tan chucha de su madre". (88). Al insulto de Isabel le siguen otros, acusando la insensatez del único empleado en la novela que aún cree en la viabilidad de una unión obrera. Enrique lo llama un "saco de huevas", Gloria un "[c]uliado envidioso" (89). Ejemplos como estos abundan en "Puro Chile".

De modo que lo que finalmente caracteriza los intercambios entre ellos no es el respeto ni el aprecio, sino el miedo, la sospecha la ira y una violencia apenas contenida -que en ocasiones se expresa físicamente. La expresión vulgar revela entonces la total impotencia de estos sujetos que no tienen otro modo de resistir o de rebelarse contra la farsa impuesta por unas reglas de comportamiento y de expresión que están hechas para otras circunstancias, o para quienes tienen la seguridad y la comodidad de no tener que preocuparse de su bienestar económico ${ }^{5}$. ¿Cómo hablar "con propiedad", o insistir en los buenos modales que alguna vez distinguió a la burguesía chilena, después de rebanarse un dedo trozando pollos, con el vómito en la boca o con las tripas fuera de control?

Resulta interesante recordar que la retórica del elogio y del vituperio (o del respeto y aprecio y del desprecio y rechazo) pertenece a la retórica epidíctica, rama de la retórica que ocupó un papel importantísimo en las letras de Antonio de Nebrija, cuya gramática española se impuso en las Américas durante los siglos XVI y XVII. Un siglo y medio más tarde, Andrés Bello, padre de la gramática latinoamericana y el estadista quien más parece haber hecho para convencer a los nuevos políticos chilenos de la superioridad de la agenda liberal política y económica, dedicó buena parte de su vida y obra a la enseñanza de la buena dicción y la corrección en el habla, convencido de que este proyecto lingüístico era fundamental para el triunfo de la democracia y del buen funcionamiento del libre mercado. Aunque Bello admitía la necesidad de permitir neologismos científicos como parte del carácter orgánico de toda lengua vivo, no dejaba de predicar la necesidad de desterrar del español americano cualquier vocablo o jerga de baja procedencia, temiendo que estos desatarían la barbarie no solo en el ámbito lingüístico sino en el ámbito social ${ }^{6}$.

Eltit ha de estar consciente, sin duda, del peso de Andrés Bello al subrayar el vaivén hiperbólico de estos personajes al borde del desempleo y del desalojo, cuyos esfuerzos por hablar correctamente no es ni mínimamente suficiente para acallar los neologismos "bárbaros" que Bello quería desterrar de todo diccionario. Es difícil saber si la autora quiso también apuntar al hecho de que detrás de la buena gramática de Bello se perfila el fantasma de Adam Smith, y no solo por ser considerado el padre del pensamiento

5 En este sentido la frágil comunidad que se arma y desarma a diario dentro de la casa está basada tanto en la necesidad de poder pagar el alquiler como en la atmósfera hobbesiana de miedo y sospecha que define las relaciones entre ellos.

6 Aunque las intenciones de Bello como nuevo republicano bolivariano eran mantener la unidad del español americano, no es difícil ver que los dialectos y neologismos que instaba a censurar y silenciar eran aquellos provenientes de los grupos étnicos y las clases populares. Sobre Bello, la gramática y el establecimiento de un orden civil, ver Eleucilio Niebles Robles "La construcción de un orden civil fundamentado en la gramática". 
liberal. Es harto conocida la fórmula sobre la que Smith funda la religión del capitalismo liberal -o del liberalismo económico: la división del trabajo + la no intervención del Estado = un libre mercado que garantice el progreso económico y social de la nación. Así lo explica Smith en An Inquiry into the Nature and Causes of the Wealth of Nations ${ }^{7}$. Menos conocida es la estrecha conexión que el economista y moralista escocés establece entre el progreso de la sociedad y del mercado y la necesidad de educar a una clase comerciante capaz de hablar con corrección y persuasión. Esto no era suficiente, sin embargo. A riesgo de simplificar un argumento algo más complejo, cabe notar que Smith consideraba que la opinión pública era de importancia capital para que la sociedad liberal pudiera dispensar con la intervención del Estado y de la iglesia, y para formar la opinión pública nada mejor que la retórica epidíctica -o el manejo del elogio y del vituperio. Gran admirador de Jonathan Swift por su uso del insulto, Smith no descuidaba el valor del ridículo para amonestar o reformar a quien necesitaba ser amonestado -aunque es de suponer que el vituperio que él imaginaba como instrumento pedagógico y moral debía estar a cargo de quienes tenían un peso moral y económico indiscutible.

En un artículo sobre la espectacularidad del tipo de violencia criminal que fascina a los medios de comunicación y hacen que se hable de Latinoamérica como una de las regiones más violentas del mundo, Rossana Reguillo explica que para entender los brotes de violencia actual en Latinoamérica hace falta prestar atención no solo a la nueva geopolítica global, sino a los efectos de la violencia epistemológica y simbólica que funda la idea y la realidad americana. La violencia simbólica ejercida por 'la palabra blanca', dice Reguillo en "Violencias y después", sigue agrediendo a sectores enteros de la población latinoamericana. En Mano de obra, el sarcasmo irónico que marca el contraste entre enunciado vacío pero socialmente aceptable del habla cortés contra la mala palabra tiene el efecto de desenmascarar el abismo comunicacional y retórico que rinde inoperante a esta comunidad obrera. Similarmente, en "El Mercado de la violencia" Mabel Moraña reflexiona sobre la "violencia epistemológica de la alfabetización que impone los modelos imperiales sobre los conquistados aplastando sus lenguas y creencias" (1), y concluye que,

quizá solo venciendo la comprensible tentación de pensar a la violencia como un mero desorden simbólico, carente de sentido y direccionalidad, caótico y errático, podamos advertir lo que las lenguas trabadas y babélicas de la violencia dicen a nuestro tiempo: qué denuncia de la violencia sistémica están vociferando, qué tipos de subjetividad las sostiene, y cómo se articulan a las profundas grietas de la modernidad (8).

7 Tanto en inglés como en español, el término "propiedad" (propriety), fue y sigue siendo sinónimo de propiedad como pertenencia, o "property". Sobre este aspecto de la obra de Smith, ver Stephen McKenna, Adam Smith. The Rhetoric of Propriety. 
En mi ensayo "Hacia una estética de la carencia: Estrategias formales de resistencia en Diamela Eltit", publicado en 2005 y escrito poco después de haber leído la novela por primera vez, llego a la conclusión de que el argot vulgar que hace estallar constantemente la narración de una posible solidaridad obrera en la segunda parte de Mano de obra es una voz de resistencia. Varios otros lectores de la novela han llegado a una conclusión similar. Como modalidad expresiva decididamente contrahegemónica, el insulto soez es señal de rebeldía, nota Jean Franco en uno de los primeros artículos sobre este aspecto de la novela. Michael Lazzara considera que el uso de este lenguaje soez "puede leerse como otro recurso poético a través del cual los sujetos violentan el lenguaje transparente, enlatado y aséptico del mercado neoliberal" (163), y Rubí Carreño señala, además, que las palabrotas reflejan un "lenguaje mestizo... replegado a su expresión más cruda" (s/p). Hoy, sin embargo, mi lectura de la maledicencia en boca de los empleados es más ambigua. Más bien inclino a pensar que la degradación que sufre la lengua en la segunda parte de la novela no es señal de rebeldía sino de frustración y creciente desesperación. Creo acertadas las palabras de Javier Moreno citadas a comienzos de este ensayo: "El lenguaje de la miseria está hecho de gruñidos... La pobreza empieza por la precariedad de la sintaxis"8. Vista desde esta perspectiva la vulgaridad furiosa en que decae la comunicación de los empleados en la segunda parte resulta mucho más angustiante que subversiva. Es convincente la conclusión de Julio Ortega al notar que la jerga obscena en que decae el habla de los empleados en la novela no es "un lenguaje propio", sino un "habla empírica, que le sirve para maldecir pero cuya herencia lo hace parte de la violencia que recibe" (s.p.).

En la entrevista ya citada, Eltit revela que en Mano de obra ella quiso explorar "cómo la desarticulación de las organizaciones laborales (el sujeto obrero, las estructuras sindicales) conducían a una pérdida de discurso, que se permuta en cambio de expresiones que remiten a la esfera de un lenguaje residual conformado básicamente por "malas palabras" o "garabatos", como decimos en Chile, y cómo ese lenguaje considerado 'violento' empieza a naturalizarse y a reemplazar amplias zonas discursivas". La pérdida de solidaridad obrera, señala Eltit en la misma entrevista, es un resultado de esta "pulverización de las articulaciones laborales", y esta, a su vez, "promueve un nuevo sujeto trabajador, que entrega su cuerpo a las leyes, al libre mercado de oferta y demanda, un sujeto inestable que debe poner en crisis la noción de comunidad laboral, el valor de la lealtad, porque su espacio-cuerpo está amenazado"9. El final de la novela parece apuntar a la repetición de la traición y a la desintegración progresiva pero inevitable del ya mermado grupo. El último refugio de una comunidad amenazada quizás

8 Ver los comentarios del autor al comentar estas palabras en Hacier Larretxea, entrevista con el autor (marzo 2013).

9 Entrevista con Claudia Posadas, "Un territorio de zozobra" (2002). 
sea una lengua común: es preocupante, por lo tanto, que al final de Mano de obra esta lengua está a punto de convertirse en gruñido.

\section{Bibliografía}

Bello, Andrés. Gramática de la lengua castellana destinada al uso de los americanos. 1847. Obras completas IV. $3^{a}$ edición. Prólogo de Amado Alonso. Caracas: La Casa de Bello, 1995. Web. Biblioteca Virtual Miguel de Cervantes, 2002. Consultado enero 10, 2014.

Carreño, Rubi. "Mano de obra, una poética del (des)centramiento". Revista Casa de las Américas, enero-marzo (2003). En línea: http://www. letras.s5.com/eltitcuba0808037.htm.

Eltit, Diamela. Mano de obra. Santiago: Editorial Planeta Chilena, 2002.

Franco, Jean. "Malas palabras: Sobre Mano de obra de Diamela Eltit". Provisoriamente: Textos para Diamela Eltit. Ed. Antonio Gómez y John Beverley. Rosario: Viterbo, 2007. 143-153. Impreso.

Larretxea, Hacier, Javier Moreno. "El Terrorismo surge de la indigencia de los escritores". Entrevista con Javier Moreno. Marzo 2013. En línea http://www.koult.es/2013/03/javier-Moreno-el-terrorismo-surge-dela-indigencia-de-los-e escritores/. Consultado mayo 10, 2015.

Lazzara, Michael J. "Estrategias de dominación y resistencia corporales: las biopolíticas del mercado en Mano de obra, de Diamela Eltit". En Letras y proclamas: la estética literaria de Diamela Eltit. Ed. Bernardita Llanos M. Santiago: Editorial Cuarto Propio, 2006. 155-163. Impreso. 2015.

McKenna, Stephen. Adam Smith: The Rhetoric of Propriety (Rhetoric in the Modern Era). Albany: State University of New York Press, 2006.

Moraña, Mabel. ___. "El Mercado de la violencia en América Latina". Web. https://www.academia.edu/8633719/_El_mercado_de_la_violencia_ en_America_Latina_Consultado 10 de mayo, 2015.

Niebles Robles, Eleucilio. "La construcción de un orden civil fundamentado en la gramática". Programas 27 (2007): s.p. Web. <https://uic-illiadoclc-org.proxy.cc.uic.

Niebylski, Dianna. "Hacia una estética de la carencia: Estrategias formales de resistencia en Diamela Eltit". La Torre: Revista de la Unversidad de Puerto Rico. 10.38 (2005): 479-599. Impreso.

"Gramáticas capitalistas, retóricas contra-hegemónicas y la prensa obrera chilena: Mano de Obra de Diamela Eltit". Pobreza y precariedad en el imaginario latinoamericano del siglo XXI. Editado Stephen Buttes y Dianna Niebylski. Santiago: Cuarto Propio: de próxima aparición.

Ortega, Julio. "El sistema de Diamela Eltit". La ciudad literaria de Julio Ortega. Web. <http://blogs.brown.edu/ciudad_literaria/2008/01/09/el-sistemade-diamela-eltit/>. Consultado 4 enero de 2015.

Posadas, Claudia "Un territorio de Zozobra: Entrevistacon Diamela Eltit. En línea: https://pendientedemigracion.ucm.es/info/especulo/numero25/ eltit Consultado enero 2004.

Reguillo, Rossana. "Violencias y después. Culturas en reconfiguración". [En línea]. <http://lanic.utexas.edu/project/etext/llilas/cpa/spring03/ culturaypaz/reguillo.pdf $>2015$. Consultado 2 marzo 2014. 
Smith, Adam. An Inquiry into the Nature and Causes of the Wealth of Nations. Produced by Colin Muir and David Widger. Project Gutenberg. E-Book. http://www.gutenberg.org/files/3300/3300-h/3300-h.htm. Consultado en numerosas ocasiones entre 1 marzo 2014 y 10 mayo 2015. 
